\title{
Fortalecimiento en los Procesos Lecto-Escritos en Primera Infancia a través de Blended-Learning
}

\section{Strengthening Reading-Written Processes in Early Childhood through Blended-Learning}

Jenny Zoraida Mora Reyes ${ }^{1 *}$ Sandra Patricia Morales Rivera ${ }^{2}$

${ }^{1}$ Colegio Alexander Fleming IED. ${ }^{2}$ Colegio Técnico Palermo IED

\begin{abstract}
En la presente innovación se pretendió ofrecer una alternativa de trabajo significativo en un ambiente de aprendizaje presencial, fortalecido a través de espacios virtuales, mejor conocido como b-learning, el cual se llevó a cabo en una institución educativa en Bogotá (Colombia), con estudiantes de preescolar o primera infancia, cuyo objetivo fue fortalecer sus competencias lecto-escritas, buscando el desarrollo y acercamiento a las mismas.

Para ello, se diseñó y evaluó este proyecto de innovación con instrumentos basados en la observación y el reconocimiento de habilidades previas frente al aprestamiento en actividades lecto-escritas, adicional se realizó una entrevista familiar, instrumentos que permitieron evidenciar, de manera empírica, el beneficio académico y motivacional de este modelo de aprendizaje en los estudiantes de primera infancia, además de involucrar a la familia en los procesos de formación.
\end{abstract}

A lo largo del estudio se encontró que los estudiantes de primera infancia fortalecieron los procesos de lectura, escritura y comunicación oral, y se evidenciaron dificultades relacionadas con acceso a computadores, compromiso de los tutores con el acompañamiento y la presentación de evidencias del trabajo en casa por parte de algunos estudiantes.

Descriptores: Lectura, B-learning, Innovación, Primera infancia.

In this innovation was intended to offer an alternative to meaningful work in an environment of classroom learning, strengthened through virtual space, better know as b-learning, which took place in an educational institution in Bogotá (Colombia), with preschool students or early childhood, whose objective was to strengthen their reading-writing skills, seeking development and approach to them.

To do this, we designed and evaluated this innovation project with observational instruments and the recognition of previous skills against readiness in reading writing activities, additional a family interview, instruments that allowed prove, empirically performed, the academic and motivational profit of this learning model in early childhood students, and additional to involve the family in the training process.

Throughout the study we found that students in early childhood strengthened the processes of reading, writing and oral communication, and found difficulties with acces to computers, tutor commitment to the accompaniment, and presentation of at home work evidence from some students.

Keywords: Reading, Writing, B-learning, Innovation, Early childhood.

\footnotetext{
*Contacto: jeymora@gmail.com

ISSN: $1696-4713$

rinace.net/reice/

revistas.uam.es/reice
}

$\begin{array}{ll}\text { Recibido: } & 7 \text { de noviembre } 2014 \\ 1^{\text {a }} \text { Evaluación: } & 20 \text { de febrero } 2015 \\ 2^{\text {a }} \text { Evaluación: } & 9 \text { de julio } 2015 \\ \text { Aceptado: } & 14 \text { de septiembre } 2015\end{array}$ 


\section{Introducción}

Desde que nace el ser humano está inmerso en un mundo rico en toda clase de estímulos y los procesos de lectura y escritura no son la excepción, sin embargo el desarrollo de estas habilidades de manera formal se han convertido para algunos maestros, padres y estudiantes en un verdadero conflicto, puesto que los niños y niñas deben interiorizar símbolos o grafías que de alguna manera no tienen sentido o razón de ser, sin embargo La presente investigación se realizó con el objeto de explorar nuevas estrategias que permitan contribuir en los procesos de aprendizaje de los niños y niñas con edades entre los 5 y 6 años, ya que se observaron dificultades en el inicio de su escolaridad formal, principalmente en procesos de lectura y escritura convencional, diferentes autores atribuyen posibles causas, entre ellas el escaso acompañamiento de sus padres o tutores y a la falta de motivación en la adquisición de estos procesos.

Teniendo en cuenta esto, se pensó en la inclusión de tecnologías en los ambientes de aprendizaje, en este caso blended-learning (b-learning).

La investigación se llevó a cabo en fases: la primera, reconocimiento del contexto social en el cual se encontraban los niños y niñas, esta incluyó un diagnóstico sobre el estado de los procesos de lecto-escritura de los estudiantes; la segunda, implementación y profundización de la estrategia tecnológica seleccionada; la tercera, de evaluación; y la cuarta de conclusiones y sugerencias.

\section{Fundamentación teórica}

\subsection{Innovación de ambientes de aprendizaje}

Debido a que la tecnología avanza a grandes pasos, es ideal en la actualidad incorporar tecnologías innovadoras al ámbito educativo con el objetivo de mejorar los procesos de aprendizaje de los estudiantes, para ello es necesario buscar estrategias de aprendizaje creativas y significativas que logren reforzar las competencias de estructuración del lenguaje en procesos lectores y escriturales en la primera infancia, no se pretende que la inclusión de la tecnología sea la panacea en la educación pero sí podemos pensar en que con el b-learning se motiven y refuercen diferentes aprendizajes, haciendo de estos procesos un camino acogedor y motivante para los estudiantes, aprovechando que las tecnologías ocupan un lugar importante en la cotidianidad de nuestra sociedad.

A partir de la definición de innovación, se realizó el planteamiento de una nueva propuesta, de vanguardia, que permitió implementar una estrategia de aprendizaje para los niños y niñas de la época, mejor llamados por Escorsa (1997, p. 21) "nativos digitales", donde afirma que la innovación es "el proceso en el cual a partir de una idea, invención o reconocimiento de una necesidad se desarrolla un producto, técnica o servicio útil hasta que sea comercialmente aceptado", y desde luego social y culturalmente admitido.

La innovación en el contexto educativo ha sido definida por varios autores, entre ellos Carbonell (2002, p. 78), quien define este aspecto como: "un conjunto de ideas, procesos y estrategias, más o menos sistematizados, mediante los cuales se trata de introducir y provocar cambios en las prácticas educativas vigente. La innovación no es una actividad puntual sino un proceso, por lo cual no se pretende que los resultados se den de inmediato, sin embargo se espera dar un paso para iniciar el cambio positivo hacia la 
modificación de concepciones, actitudes y métodos, contribuyendo al cambio desde los espacios de aprendizaje, aulas, la institución y en general la comunidad educativa, alterando la realidad y mejorando la práctica educativa y por ende la calidad de ésta”. Desde esta perspectiva se pretendió incluir nuevas estrategias de enseñanza, buscando fortalecer no sólo la adquisición de habilidades en el proceso de lecto-escritura, sino también en procesos de pensamiento crítico desde la primera infancia.

Para innovar o crear es indispensable el conocimiento del contexto donde se desarrolla la idea, con miras a construir estrategias novedosas, donde se integren los recursos tecnológicos, escapando al ambiente educativo tradicional y convencional buscando un impacto transformador en la comunidad educativa; se considera que es desde el contexto escolar, donde se eliminan las brechas sociales y la desigualdad en la utilización, acceso e implementación de los recursos tecnológicos en los procesos de aprendizaje y en la vida diaria, fomentando desde allí su uso y adecuada utilización, buscando con esto acercar e incorporar las TIC a la realidad de los estudiantes desde los primeros grados de escolaridad. Es normal pensar que todos los individuos tienen amplio acceso a las tecnologías por el auge y la incorporación de estas al entorno social y cultural, sin embargo según informes de organizaciones internacionales esta no es la realidad.

El informe de la UNESCO (2005) expresa que hoy en día sólo el 11\% de la población mundial tiene acceso a internet, que el 90\% de las personas conectadas vive en países industrializados, lo que deja a una gran parte de la población de América Latina sin entrada a estos recursos que están revolucionando todas las actividades, no solo educativa sino también social y culturalmente.

Debido al cambio de paradigmas educativos, al crecimiento y a la constante evolución de la tecnología en nuestro medio, es ideal buscar nuevos ambientes de aprendizaje que transformen la escuela, motivando a los estudiantes a este proceso, pues es innegable que la tecnología, plantea nuevo retos tanto para la sociedad como para la cultura en esta era tecnológica, es por ello que la escuela debe ser el lugar donde se promueva el uso de las TIC en el proceso de formación, y en este caso se fomente el uso de estas en el desarrollo de los procesos comunicativos de los estudiantes, con fines educativos, ya que en este contexto el uso de la tecnología: móviles, tabletas, entre otros, se da para fines recreativos, es decir los niños y niñas acceden generalmente a juegos interactivos o videojuegos.

Es innegable que los procesos mentales de las nuevas generaciones son muy activos, porque existe en ellos una actitud investigativa, que se va perdiendo con el tiempo, es importante que desde los primeros años se opte porque el constructo de conocimiento se lleve a cabo a partir de la experimentación y la indagación. Desde hace ya varios años se hace urgente una innovación en la educación, en general de América Latina, ya que el mundo cambia de manera vertiginosa, las tecnologías, el modelo de sociedad, de familia, la cultura, pero la educación se quedó en el siglo XIX, no se desconoce que esta historia de la educación es importante porque con ella han crecido varias generaciones, pero se hace urgente un proceso innovador, la innovación "es el acto de creación, que considera experiencias pasadas, implica instauración multidimensional de nuevos desarrollos sociotécnicos" (ANUIES, 2004, p. 10), reconociendo que la innovación contribuye a mejorar, desde la práctica pedagógica y trasciende a los modelos sociales.

Sin embargo al introducirse aún más en los resultados del b-learning y más exactamente al uso de las TIC en educación se puede decir que estos no han sido concluyentes, ya que 
faltan estudios sistemáticos y llevados a cabo por largo tiempo para poder hacer una afirmación inequívoca del uso de las tecnologías en la educación, Cox y Marshall (2007).

\subsection{Modelos de gestión de aprendizaje}

Con miras a fortalecer los procesos de lectura, escritura y el pensamiento crítico en los estudiantes de preescolar, se implementaron diferentes modelos como el activo, el participativo, que permitieron desarrollar estos procesos; ya que se nos recomienda "que no debemos limitar nuestros procesos de enseñanza a un modelo único, por atractivo que sea a primera vista, porque no hay modelo capaz de hacer frente a todos los tipos y estilos de aprendizaje" (Ramírez, 2012, p. 6). Sin embargo, el planteamiento se basa principalmente en modelos de gestión del conocimiento tecnológico, en los cuales las TIC tienen un papel importante en la innovación como lo planteado por los autores Sallis y Jones (2002) pero el papel presencial del docente no se puede dejar de lado.

El b-learning entendido como "un enfoque pedagógico que combina la eficacia y las oportunidades de socialización de la clase con la tecnología para aprovechar las posibilidades de aprendizaje" (Dziuban, Hartman y Moscal, 2004, p. 3), ofreció la oportunidad de que los estudiantes pudieran ser incorporados de forma más activa en su proceso de aprendizaje, además, como los estudiantes son pequeños se logró vincular a los padres de familia, se ayudó a superar el aislamiento del estudiante, para quienes son retraídos y apáticos a la participación en clase, se redujeron barreras espaciales y temporales, se maximizó la productividad, especialmente a partir de la construcción social del conocimiento, se fomentó la retroalimentación, el aprovechamiento permanente de los recursos didácticos y material disponible en la red. En sí, se tomó lo mejor de ambos ambientes: presencial y virtual mejorando las capacidades de los estudiantes en su parte analítica, autónoma y de comunicación, para un mejor desempeño en su trabajo colaborativo.

Debido a que se encontraron experiencias exitosas en la escuela primaria en los cuales el b-learning fue apoyo para optimizar procesos, el grupo investigador usó herramientas de comunicación asincrónicas, se utilizaron recursos audiovisuales como animaciones y video cuentos, entre otros, buscando con ellos el acompañamiento en casa, acudiendo además a las clases presenciales Coaten y Marsh (2003), para mejorar su habilidad al momento de leer y comprender. Para Garrison y Kanuka (2004, p. 98), el b-learning integra dos posibilidades, educación sincrónica y asincrónica; facilitando una experiencia de trabajo colaborativo e independiente en los estudiantes. El trabajo colaborativo se llevó a cabo en el aula, debido a la edad de los estudiantes.

Con respecto a los procesos de lectura y escritura en los niños y la función social que estos poseen podemos decir que: se dan de manera natural y se modifican en el transcurso de la escolaridad y de la vida misma, de acuerdo a las experiencias sociales y culturales de su entorno, van determinando su desarrollo, en consecuencia, como lo afirman Bajtín (1998, p. 390) y Lerner (2001, p. 2), "la escuela debe generar un ambiente o " micro comunidad" donde las prácticas propuestas guarden "cierta fidelidad a la versión social" (no escolar), por lo cual la escuela debe estar inmersa en la sociedad y la sociedad en la escuela.

La etapa escolar se ocupa entonces de dos tipos de prácticas de lectura y escritura, una que responde a actividades socio-culturales extraescolares y otra a aquellas propias del mundo académico, no se pueden centrar los procesos lecto-escriturales solamente en 
función de la escuela, "la escritura es importante en la escuela porque lo es fuera de ella y no viceversa" (Ferreiro, 1999, p. 163). La escritura y la lectura son unas de las formas de lenguaje que propenden por la inclusión a la sociedad; al respecto, Lerner (2001) plantea:

Esta divergencia corre el riesgo de conducir a una situación paradójica, de esta manera, si
la escuela enseña a leer y escribir con el único propósito de que los alumnos aprendan a
hacerlo, ellos no aprenderán a leer y escribir para cumplir otras finalidades (esas que la
lectura y la escritura cumplen en la vida social); si la escuela abandona los propósitos
didácticos y asume los de la práctica social, estará abandonando al mismo tiempo su función
enseñante. (p. 3)

Es por ello que se pensó en la tecnología como una herramienta, ya que su uso cotidiano motiva a los estudiantes en los diferentes aprendizajes y los acerca más al uso de las TIC incorporando estas a esa función social que tiene la lectura y la escritura, involucrando a la escuela en procesos socio-culturales que van más allá de su entorno inmediato, conduciéndolos por la cultura digital, que crece a ritmos cambiantes y acelerados, preparándolos para afrontar la realidad.

Cuando se habla de procesos y prácticas de lectura y escritura, se refiere no sólo al proceso de codificación y decodificación de grafismos, sino al proceso de leer y entender el mundo, su entorno, desde su propia perspectiva y desde sus propias experiencias de vida, el b-learning es entonces pensado como un ambiente en el que el niño se acerca de manera lúdica a la tecnología, al reconocimiento de su mundo y a los procesos de lectoescritura, involucrando además a sus familias en sus procesos cognitivos y en el uso responsable de las TIC.

En esta investigación se tuvo en cuenta los resultados de los procesos comunicativos, de comprensión y producción textual, de esta manera se evidenció el impacto del proyecto en los estudiantes y la propuesta misma, además de la interiorización en el manejo de las TIC; la forma de evaluar estos procesos se realizó de manera continua, cualitativa y formativa, garantizando con ello que los estudiantes que presentaron dificultades en el proceso superaran sus falencias.

\section{Investigaciones de Innovación Educativa}

\subsection{Recursos educativos abiertos en ambientes enriquecidos con tecnologias}

Ésta investigación, Recursos educativos abiertos en ambientes enriquesidos con tecnologías: innovación en la práctica educativa, investigadores María Soledad Ramírez Montoya y José Vladimir Burgos Aguilar, se llevó a cabo, bajo el método cualitativo, con el estudio de seis casos de dos profesoras de bachillerato que aplicaron Recursos Educativos Abiertos (REA) del Khub en su clase; éste procedimiento consiste en explorar documentos o material multimedia con fines relacionados con la educación como la enseñanza, el aprendizaje, la evaluación y la investigación cuya principal característica es que son de acceso libre y por lo general bajo licencia abierta siendo el Khub un distribuidor de conocimiento que facilita un catálogo de colecciones de recursos de aprendizaje entre universidades de diferentes países. Los instrumentos para recolectar la información fueron dos: la observación y la entrevista semiestructurada. Se exploraron dos unidades de análisis: la apropiación tecnológica y los REA.

Se investigó la práctica educativa de 3 docentes en instituciones de educación superior, una pública y dos privadas, encontrándose que la incorporación de REA tiene un 
impacto positivo en el proceso de enseñanza-aprendizaje, ya que fomenta la exploración interactiva, la colaboración entre alumnos y promueve el aprendizaje significativo. Sin embargo, es condición necesaria que los alumnos tengan disposición por aprender. La implementación de los REA dentro de las actividades del tema de programación orientada a objetos tuvo una aceptación positiva en los alumnos ya que en los tres casos fue una actividad novedosa. Sin embargo, faltó tiempo para ahondar más en los temas y trabajar más a fondo con los recursos. Se pretende que este estudio pueda tener implicaciones en otras prácticas educativas que deseen incorporar REA en sus planes de estudio.

\subsection{Medialab Eafit. Un ejemplo de innovación educativa}

El periodista Luis Carlos Pérez Gómez realizó una investigación de la experiencia que es ejemplo de innovación, ubicada en la universidad Eafit, en la ciudad de Medellín (Colombia), refiriéndose al Medialab como un laboratorio de medios, y sus creadores hablan así de éste: "En un principio podría decirse que es un proceso de creación colectiva o una suma de complicidades", dice el profesor Mauricio Vásquez, uno de los encargados del Medialab, que luego añade que "es una potencial incubadora de spin off, un generador de ideas, de prototipos que pueden ser luego desarrollados y explotados comercialmente".

En el caso particular de Eafit, el Medialab representa una oportunidad para que sus estudiantes ensayen, concreten productos y buenas ideas. De acuerdo con Vásquez (2010), licenciado en Filosofía y Letras de la Universidad de Caldas:

\footnotetext{
También es un espacio para cometer errores y equivocarse. Nosotros no nos damos la oportunidad en los contextos muchas veces comerciales, e incluso académicos, de cometer errores. El Medialab permite eso, porque creemos que en la medida en la que ellos se equivoquen, van a aprender de esos errores. (Entrevista 1)
}

Se observa un interés especial en cómo lo digital ayuda a contar, ayuda a narrar, a interpretar el mundo, a explicarlo, a construir visiones de mundo. Y el Medialab "ha sido no sólo una herramienta, sino un medio, un espacio, una forma de acercarse al mundo digital y de acercarse a la cultura digital a través de metodologías prácticas del juego, de poner la teoría al servicio de las oportunidades" (Pérez Gómez, 2013, p. 1).

Es por eso que desde el Medialab surgió la idea de impactar en distintas comunidades, para poner estas nuevas prácticas académicas al servicio de la ciudad. Gracias a este proyecto, alrededor de 300 estudiantes de la Institución Educativa Robledo Aures, recibieron capacitación en periodismo digital, radio, televisión y redes sociales por parte de estudiantes del pregrado en Comunicación Social de Eafit. Además, 120 niños y niñas de cuarto grado de los colegios públicos de Itagüí participaron en talleres de alfabetización tecnológica e incluso produjeron su propio documental utilizando computadoras portátiles.

\subsection{Experiencias exitosas en ambientes b-learning}

El b-learning como una experiencia en una escuela secundaria en Australia, ha sido una experiencia enriquecedora, han creado redes de apoyo gracias a las herramientas tecnológicas, la más usada es el internet. La adopción de un enfoque de aprendizaje combinado ofrece el atractivo de la combinación de diferentes elementos utilizando el poder de las TIC al tiempo que conserva un toque humano de aprendizaje. 
El modelo de aprendizaje mixto debe describir una planificada y deliberada actividad educativa que integra el aprendizaje centrado en el estudiante, de manera presencial y el aprendizaje con el móvil y web - basada enfoques basados en línea, en cada alumno y sus necesidades específicas. Se llevó a cabo un plan piloto en una escuela victoriana de educación rural se basan en la necesidad de aprendizaje en línea contando con infraestructuras, políticas y prácticas para facilitar el aprendizaje en el siglo XXI (Herold, 2014).

Se utilizó la herramienta ULTRANET que apoya sus objetivos proporcionando espacios de colaboración en línea, herramientas y recursos digitales en un aprendizaje que mejore el aula física. Esta proporcionó oportunidades para estudiantes, padres y educadores para compartir información, colaborar y comprometerse en el aprendizaje en un espacio seguro.

El ULTRANET ofrece entornos de aprendizaje en línea asincrónico y sincrónico a todas las escuelas victorianas del gobierno. Por otra parte los profesores tendrán que ser formarse y especializarse rápidamente para hacer frente a la enseñanza virtual (Department of Education Childhood Development).

En Costa Rica se encontró una investigación, cuyos autor Solano (2013) realizó primero una breve indagación acerca de la manera cómo las docentes de preescolar han ido introduciendo las tic al trabajo con los estudiantes Primero se realizó un acercamiento a instituciones educativas que habían incluido la tecnología al aula, se escogieron instituciones de educación preescolar públicas que tuvieran computadoras en el aula para el uso de los estudiantes. Se entrevistaron a las directoras de las instituciones escogidas, y se realizaron observaciones en las aulas todo esto con el fin de evidenciar, cuál era el uso que le daban las docentes a las TIC en el preescolar.)

Con ayuda de estudiantes de trabajo comunal universitario del Centro de Investigaciones en Neurociencia se diseñó un software educativo para fomentar en los estudiantes de preescolar el trabajo colaborativo y las destrezas en el manejo del computador. En la siguiente fase se tomó un grupo de estudio y se trabajó con el prototipo del software educativo, los estudiantes tuvieron la oportunidad de interactuar con éste, y se realizaron las modificaciones pertinentes. Posteriormente se desarrollaron talleres para mejorar el software teniendo en cuenta los intereses de las instituciones.

Dentro de los aspectos que encontraron concluyeron que: la alfabetización tecnológica debe abarcar alumnos y docentes; involucrando a las maestras en la construcción de herramientas virtuales, la incorporación de la computadora dentro del aula colabora en aumentar sus niveles de atención y concentración por medio del uso de distintos programas, recursos que también se han llegado a convertir en un elemento más, de motivación para que los estudiantes quieran asistir a la institución. Las docentes consideraron que el uso de la computadora dentro del aula, ofrece materiales y oportunidades complementarias que pueden favorecer el ejercicio de habilidades de motricidad fina y coordinación psicomotriz, contribuyendo así a reforzar el trabajo que se realiza con otros materiales en diversos espacios del salón de clase (Paniagua, 2013).

Se encontró también una investigación realizada por la docente Jenny Villareal (2011) en Floridablanca, donde la docente busca utilizar de manera asertiva las TIC con las que ha sido dotada la institución, y mediante el modelo b-learning, desarrollo procesos de manera lúdica participativa y motivadora, esta fue una investigación acción donde la 
docente era además la investigadora, se obtuvieron resultados que ella describe como gratificantes, ya que no sólo los niños cambiaron su actitud hacia sus pares y adultos sino también hubo un mayor aprovechamiento y apropiación de las herramientas tecnológicas.

En una escuela Europea más exactamente en Milán (Italia) en la institución Bilingual European School, se incluyeron herramientas tecnológicas en cada aula, que convirtieron en un continuo desarrollo de habilidades apropiadas para las edades y competencias que se enseñan y aplican a los conceptos y líneas de investigación de los estudiantes en sus clases, el moderno laboratorio de informática no actúa como el fin, sino como un medio, ya que no se limita solo a la instrucción sino que está inmerso en todas las actividades de clase.

La disponibilidad constante de diferentes herramientas tecnológicas para los estudiantes desarrolla en ellos habilidades en la creación, colaboración y comunicación en una variedad de formas reales y auténticas. Esta visión de su modelo pedagógico buscó convertir a sus estudiantes en ciudadanos digitalmente responsables, reconociendo los beneficios y limitaciones de la tecnología, la utilización de herramientas tecnológicas de manera crítica.

\section{Método de Investigación del Proyecto}

El proceso lecto-escrito desarrollado es multimodal puesto que en el aula se llevaron a cabo diferentes tareas y actividades apoyadas con medios tecnológicos y recursos multimedia (audios, videos, imágenes, juegos interactivos) y en casa se llevó a cabo de manera virtual con ayuda de los padres, apoyado en recursos como blogs, videos y presentaciones, sugeridas por las docentes.

El tipo de investigación desarrollado fue cualitativo, pues lo que se pretendía era demostrar si con el apoyo de las TIC se fortalecían procesos de lectura y escritura, las investigadoras participaron de manera activa durante la investigación, la recolección de datos se llevó a cabo a través de entrevistas, observación directa y encuestas.

Para evaluar la pertinencia del proyecto se realizó cuadro de triple entrada, con el cual se pretendió evaluar los procesos lecto-escriturales de los estudiantes y el desarrollo de las habilidades comunicativas (anexo 1).

\section{Diseño del Proyecto de Modelos de Gestión de Aprendizaje}

El modelo seleccionado fue el de aprendizaje b-learning ya que en este caso es responsabilidad del docente la planificación, implementación y evaluación de la enseñanza Eggen y Kauchak (1999), citado por Ramírez (2012). Los modelos de gestión de aprendizaje están definidos como:

las formas de transferir el conocimiento desde el lugar donde se genera hasta el lugar donde se va a emplear. Implica el desarrollo de las competencias necesarias al interior de la planeación didáctica para compartirlo y utilizarlo entre sus miembros, así como para valorarlo y asimilarlo si se encuentra en el exterior de éstas y los modelos de gestión innovadores implica nuevas formas de diseñar los ambientes de aprendizaje. (Ramírez, 2011 , p. 39) 
Y para el caso el b-learning es totalmente innovador en la institución. Un ejemplo de modelo de gestión de aprendizaje innovador que está relacionado con prácticas abiertas, denominado Oportunidad (2012) ¿Cómo la apertura al público de los recursos educativos puede aportar nuevas posibilidades de aprendizaje a los estudiantes tanto en el campus universitario como más allá de las paredes de las instituciones? Impactó a nivel regional, nacional o local, institucional y a nivel de usuarios. El proyecto pretende fomentar la adopción y puesta en acción de las prácticas educativas abiertas (PEA) y de los recursos educativos abiertos (REA) en América Latina como un enfoque ascendente para desarrollar un Espacio Común y Público de Educación Superior. La iniciativa también abre la posibilidad de ofrecer recursos educativos gratuitos para los autodidactas, en términos de aprendizaje informal y de formación continua.

Las dimensiones que incluye la agenda son:

- Enfoques pedagógicos para REA. Incluidos los aspectos de enseñanza y aprendizaje y enlaces con el aprendizaje social, aprendizaje constructivo entre pares;

- Soluciones tecnológicas para REA. Incluidas tecnologías clave, estándares, especificaciones (es decir, metadatos, publicación, consulta) e infraestructura;

- Marcos Organizativos y Procedimientos. Los roles de los diferentes actores en las instituciones para la construcción, reutilización y mezcla de REA, y procedimientos rentables de REA;

- Nuevos modelos de financiación institucional y sostenibilidad (FMS). Cómo las PEA contribuyen a generar nuevos recursos y modelos institucionales de negocio con el fin de asegurar la sostenibilidad a largo plazo de las iniciativas.

Las instituciones de educación superior, desarrollaran estas dimensiones de acuerdo a sus capacidades. La agenda presenta directrices estratégicas para la apertura en la Educación Superior, el diseño de políticas y acciones destinadas a maximizar los beneficios de la utilización, reutilización y remezcla de Recursos Educativos Abiertos (REA) para el desarrollo de los cursos universitarios como un medio para abrir el acceso al conocimiento.

\subsection{Etapa diagnóstica}

Se tomaron en cuenta varios tópicos como punto de partida, realizando prueba diagnóstica, en la cual se evidenció la etapa de lectura y escritura en la que se encontraban los niños y niñas. Se analizaron las calificaciones obtenidas por los estudiantes durante el período académico. Se realizó entrevista semiestructurada a los docentes con el objeto de reconocer particularidades de los escolares, como son niveles de participación en clase, comprensión lectora, disponibilidad y adaptabilidad a la vida escolar, procesos y ritmos de aprendizaje.

En la etapa diagnóstica de los procesos de escritura se realizaron actividades de interpretación pictográfica, en donde el estudiante debía escribir una frase según la imagen, la orden fue: "que puedes decir de la imagen" (sello), después de verbalizarla "ahora escríbela", en la cual los estudiantes se limitaron a escribir las palabras que correspondían a cada dibujo, en la observación de esta actividad se evidenció que algunos estudiantes aún se encuentran en etapa de garabateo, y otros en etapas pre-silábicas (Ferreiro y Teberosky, 2003). 
Dentro de la etapa diagnóstica también se realizó la lectura del cuento "La Selva loca" de Tracey y Andrew Rogers, se realizó lectura de imágenes, los estudiantes narraron el cuento de acuerdo a las imágenes, realizando también lectura inferencial (Marmolejo y Jiménez, 2006). Cabe aclarar que estas imágenes fueron proyectadas en el computador con pantalla (monitor) grande.

\subsection{Implementación de la propuesta}

Se realizaron actividades en forma constante, 3 o 4 veces en la semana, (dependiendo del cronograma institucional), donde la principal actividad fue la realización de actividades con apoyo tecnológico, como es el computador, desarrollando procesos de lectura y escritura, lectura de imágenes proyectadas en el computador con pantalla (monitor) grande, proyección de videos y a diario, los 20 minutos iniciales de la jornada escolar donde se realizan actividades llamadas ABC (Actividades Básicas Cotidianas) en las que se saluda, se hace la oración, se dan a conocer las actividades del día y sus objetivos, se realizó la proyección de un video de alfabeto a abecedario indicando en nombre de cada grafía y el sonido correspondiente. Esta actividad fue concretamente conductual, los estudiantes relacionaban la grafía, el sonido y nombre de las letras, repitiendo estos según la indicación del video o la docente.

Como el tema general eran los medios de comunicación, en la semana se trabajó la letra "m", se realizaron diferentes actividades buscando dicha consonante, en diferentes contextos: en anuncios publicitarios, en el comercio existente en el barrio, en los nombres de los compañeros; realizando el análisis de cómo sonaba la letra con cada vocal y escribiendo diferentes palabras que inician con estas sílabas. Algunos estudiantes pasan y escriben en el tablero las letras que corresponden a cada palabra y los compañeros deciden si esa es la letra que sigue para formarlas correctamente, finalmente la docente leía las palabras que habían escrito, realizando las correcciones de manera oral para que ellos evocaran la grafía correcta, en el cuaderno los estudiantes transcribieron las palabras del tablero, inicialmente cómo las escribían los compañeros y luego con las correcciones, luego realizaban el dibujo correspondiente a cada palabra.

Como actividad de evaluación de la propuesta se entregó a cada estudiante cuatro viñetas con una secuencia del cuento "caperucita roja" de los Hermanos Grimm, ellos debían escribir la historia, mostrando el avance en los procesos escriturales.

La actividad realizada con los padres consistió en la entrega de los link o ligas de internet, para ver los videos de cuentos, discutirlos en familia y generar algún tipo de evidencia (carteleras, dibujos, escritos, entre otros). De los nueve estudiantes de la prueba, seis estudiantes realizaron las actividades con los padres, ellos escribieron en una hoja aparte y los estudiantes transcribieron en la hoja donde presentaron la evidencia, a los otros tres estudiantes, los padres les hicieron la tarea y no tuvieron la oportunidad de exponer su trabajo a los compañeros, ya que la actividad debía ser realizada por ellos.

Algunos padres se mostraron muy entusiasmados, acompañaron a sus hijos en la actividad y en general la presentación de los trabajos fue buena, pero otros padres, los de tres estudiantes más exactamente, ayudaron a sus hijos en la lectura de los cuentos, pero no realizaron las actividades de escritura. Durante la evaluación de la actividad que se realizó en casa, la totalidad de estudiantes contestaron las indagaciones de la docente, y narraron el cuento que más le había gustado, evidenciando la comprensión de las lectura realizadas Smith (1980), citado por Dubois (1991). 


\subsection{Método de evaluación de la intervención}

El grupo de trabajo constó de 9 estudiantes escogidos intencionalmente, tomados como una muestra representativa (Hernández, Fernández y Baptista, 2006), puesto que en la selección se tuvo en cuenta los estudiantes que asistieron con mayor frecuencia, ya que en la institución existe una problemática general, y es que los estudiantes faltan a clases con regularidad, debido a problemas de salud, climáticos o familiares. Los niños se encuentran entre los 5 y 6 años de edad, las circunstancias familiares son diferentes, por lo cual se realizó una entrevista delimitando las características socio-culturales de las familias (anexo 2), y con ritmos de aprendizaje diferentes, para que no hubiese sesgo en los resultados.

El método con el que se evaluó la intervención fue la observación directa además de las entrevistas (Stake, 2004), se realizó una encuesta a los padres para conocer sus condiciones socioeconómicas y su perspectiva hacia las habilidades lecto-escriturales de sus hijos. Se realizó el análisis de la propuesta de acuerdo a los resultados obtenidos por instrumentos diagnósticos, las encuestas (tabla 1) antes de la implementación del proyecto y la revisión de los teóricos que apoyan la propuesta.

Tabla 1. Resultados de la encuesta

\begin{tabular}{|c|c|c|c|c|c|c|c|c|c|c|c|}
\hline & & & $\mathrm{N} 1$ & $\mathrm{~N} 2$ & $\mathrm{~N} 3$ & $\mathrm{~N} 4$ & $\mathrm{~N} 5$ & N6 & $\mathrm{N} 7$ & $\mathrm{~N} 8$ & N9 \\
\hline \multirow{3}{*}{ Unidad Familiar } & & Padre & & & & & & & & & \\
\hline & & Madre & & & & & & X & & X & \\
\hline & & Ambos padres & $\mathrm{X}$ & $\mathrm{X}$ & $\mathrm{X}$ & $\mathrm{X}$ & $\mathrm{X}$ & & $\mathrm{X}$ & & $\mathrm{X}$ \\
\hline \multirow{3}{*}{ Hábitos Lectores } & & Cuentos & $\mathrm{X}$ & $\mathrm{X}$ & $\mathrm{X}$ & $\mathrm{X}$ & & & $\mathrm{X}$ & & \\
\hline & & Libros & & & & & & & & & \\
\hline & & Otros & & & & & & & & & $\mathrm{X}$ \\
\hline \multirow{6}{*}{$\begin{array}{l}\text { Percepción } \\
\text { Lecto-escritora }\end{array}$} & \multirow{2}{*}{ ¿Su hijo lee? } & $\mathrm{Si}$ & & & & & & $\mathrm{X}$ & $\mathrm{X}$ & & $\mathrm{X}$ \\
\hline & & No & $\mathrm{X}$ & $\mathrm{X}$ & $\mathrm{X}$ & X & $\mathrm{X}$ & & & $\mathrm{X}$ & \\
\hline & \multirow{4}{*}{$\begin{array}{l}\text { ¿Su hijo } \\
\text { escribe? } \\
\text { ¿Puede usted } \\
\text { leer lo que su } \\
\text { hijo escribe? }\end{array}$} & $\mathrm{Si}$ & $\mathrm{X}$ & $\mathrm{X}$ & $\mathrm{X}$ & $\mathrm{X}$ & $\mathrm{X}$ & $\mathrm{X}$ & $\mathrm{X}$ & $\mathrm{X}$ & $\mathrm{X}$ \\
\hline & & No & & & & & & & & & \\
\hline & & $\mathrm{Si}$ & $\mathrm{X}$ & $\mathrm{X}$ & $\mathrm{X}$ & $\mathrm{X}$ & $\mathrm{X}$ & $\mathrm{X}$ & $\mathrm{X}$ & $\mathrm{X}$ & \\
\hline & & No & & & & & & & & & $\mathrm{X}$ \\
\hline \multirow{9}{*}{$\begin{array}{l}\text { Medios } \\
\text { Tecnológicos }\end{array}$} & \multirow{2}{*}{$\begin{array}{l}\text { ¿Aprende con } \\
\text { ellos? }\end{array}$} & $\mathrm{Si}$ & & $\mathrm{X}$ & & $\mathrm{X}$ & $\mathrm{X}$ & $\mathrm{X}$ & $\mathrm{X}$ & $\mathrm{X}$ & $\mathrm{X}$ \\
\hline & & No & $\mathrm{X}$ & & $\mathrm{X}$ & & & & & & \\
\hline & \multirow{7}{*}{$\begin{array}{l}\text { ¿Qué medios } \\
\text { tecnológicos } \\
\text { usan? }\end{array}$} & Celular & $\mathrm{X}$ & $\mathrm{X}$ & $\mathrm{X}$ & $\mathrm{X}$ & $\mathrm{X}$ & $\mathrm{X}$ & $\mathrm{X}$ & $\mathrm{X}$ & $\mathrm{X}$ \\
\hline & & Televisión & $\mathrm{X}$ & $\mathrm{X}$ & $\mathrm{X}$ & $\mathrm{X}$ & $\mathrm{X}$ & $\mathrm{X}$ & $\mathrm{X}$ & $\mathrm{X}$ & $\mathrm{X}$ \\
\hline & & $\mathrm{PC}$ & $\mathrm{X}$ & & $\mathrm{X}$ & $\mathrm{X}$ & $\mathrm{X}$ & & $\mathrm{X}$ & $\mathrm{X}$ & $\mathrm{X}$ \\
\hline & & Portátil & & & & & & & $\mathrm{X}$ & & \\
\hline & & Tableta & & & $\mathrm{X}$ & & & & $\mathrm{X}$ & & \\
\hline & & Video juegos & $\mathrm{X}$ & & & $\mathrm{X}$ & $\mathrm{X}$ & & $\mathrm{X}$ & & \\
\hline & & Otros & & & & & & & & & \\
\hline \multirow{2}{*}{\multicolumn{2}{|c|}{ ¿Poseen internet? }} & $\mathrm{Si}$ & $\mathrm{X}$ & $\mathrm{X}$ & $\mathrm{X}$ & $\mathrm{X}$ & & & $\mathrm{X}$ & $\mathrm{X}$ & \\
\hline & & No & & & & & $\mathrm{X}$ & $\mathrm{X}$ & & & $\mathrm{X}$ \\
\hline \multirow{3}{*}{\multicolumn{2}{|c|}{$\begin{array}{l}\text { ¿Quién apoya el proceso } \\
\text { académico? }\end{array}$}} & Padre & $\mathrm{X}$ & $\mathrm{X}$ & $\mathrm{X}$ & $\mathrm{X}$ & & & & & $\mathrm{X}$ \\
\hline & & Madre & $\mathrm{X}$ & $\mathrm{X}$ & $\mathrm{X}$ & & & $\mathrm{X}$ & $\mathrm{X}$ & $\mathrm{X}$ & $\mathrm{X}$ \\
\hline & & Otros & & & & & $\mathrm{X}$ & $\mathrm{X}$ & & $\mathrm{X}$ & \\
\hline
\end{tabular}

Fuente: Elaboración propia. 


\section{Resultados}

Dentro de la etapa diagnóstica se hace evidente la falencia de los estudiantes en la lectura inferencial, puesto que realizaron descripción de las imágenes y verbalizaron los imaginarios de lo que allí sucedía, pero se mostraron inseguros y dispersos, ante las indagaciones de la docente, acerca de lo que no estaba plasmado en las imágenes.

Debido a la falta de agilidad en algunos estudiantes y el poco tiempo para la realización de estas actividades por las dinámicas de la institución, no se permitió la fluidez en el avance del proyecto sin embargo al momento de la elaboración del documento se había trabajado la letra "m" y se inició con medios de comunicación como el teléfono y el televisor y las actividades con la letra " $t$ "; pese a esto en algunos casos los estudiantes se apropiaron de los conceptos y realizaban seudolecturas, de textos cercanos como: que decía en las carteleras de la institución, cuando era la fecha de vencimiento del refrigerio, que decía en las circulares enviadas a los padres, narración de cuentos, entre otras.

Se evaluó la motivación, concentración e independencia que los estudiantes mostraron durante la implementación de la propuesta (anexo 3). Las evaluaciones cualitativas (observación directa) y cuantitativas realizadas a los estudiantes consistente en una sencilla prueba escrita, tanto en la etapa diagnóstica, como en la etapa de resultados. Se realizó observación directa del proceso (anexo 4).

Durante el desarrollo del proyecto de innovación se realizó una entrevista a los padres de familia con el fin de conocer los procesos de acompañamiento en la lectura y así mismo conocer más a fondo sobre la problemática detectada, e indagar con respecto a las ideas que se tienen en los hogares hacia la lectura, para esto se tomó una muestra de 9 estudiantes. La entrevista evidenció que el $22 \%$ de hogares estaba conformado solo por uno de los padres y el otro $78 \%$ por ambos padres, sin embargo se pudo identificar que el $34 \%$ el proceso académico es apoyado solo por la madre inclusive si el padre vivía con ellos, el padre apoyaba el proceso sólo en un $11 \%$ y ambos padres participaban de este proceso en un $44 \%$ y contrario a la percepción inicial solamente en el $11 \%$, el acompañamiento académico era realizado por terceras personas; también se evidenció que en los hogares se leía en un $66 \%$ y $34 \%$ no realizaban ninguna clase de lectura, en las familias lectoras la mayoría, $72 \%$ leían cuentos y el $28 \%$ otra clase de lecturas, el $66 \%$ de las familias entrevistadas cuentan con el servicio de internet y el $78 \%$ creían que a través de tecnología se puede aprender, por otro lado pensando en la viabilidad de utilizar medios tecnológicos como elementos de apoyo los padres contestaron que los implementos tecnológicos que más utilizan son: el celular un $100 \%$, el computador un $72 \%$, la televisión un $100 \%$ y la tablet un $22 \%$.

La implementación del proyecto fortalecimiento de procesos lecto-escritos en primera infancia a través de b-learning, consolidó procesos tanto de lectura como de escritura en los estudiantes, superando etapas del garabateo y pre silábicas, como se evidencia en los análisis de los procesos escriturales de diagnóstico y post a la implementación del proyecto, pasando a etapas pre silábicas, silábicas y alfabéticas (Ferreiro y Teberosky, 2003). Esto dependió del ritmo de aprendizaje de los estudiantes, evidenciando los alcances del proyecto en tan poco tiempo. 
En el análisis de la implementación del proyecto es conveniente tener en cuenta algunas de las premisas con las que se inició este proyecto, respecto a los preconceptos de que los estudiantes de preescolar van desarrollando, procesos casi innatos de lectura inferencial e imágenes esto se vio reflejado en los resultados obtenidos en la tabla de análisis 3; actividades por 3 componentes y la tabla de Observación directa de clase siendo estas clases de lectura las bases, para la iniciación a la lectura y a la comprensión lectora (Aparicio y Mantilla), por lo cual se hace evidente que el fortalecimiento de la lectura inferencial y la lectura de imágenes debe ser una constante en el de desarrollo de las clases, siendo el b-learning una propuesta asertiva y motivante para los estudiantes.

El desarrollo de procesos en la comprensión lectora es importante los estudiantes, avanzaron en procesos de lectura inferencial, viéndose reflejado en la tabla de observación de clase. Se ha encontrado que la comprensión de lectura en el nivel inferencial es importante para identificar información no explícita en los textos, ayuda a encontrar secuencias lógicas de información y recuperar información. No poseer ciertas habilidades para comprender inferencialmente puede provocar problemas en la comprensión de lectura. Las habilidades de comprensión tiene sus inicios en el lenguaje oral por lo cual pueden empezar a identificarse tempranamente ciertas dificultades y trabajar en el entrenamiento de estas (Marmolejo y Jiménez), con un trabajo constante y motivante con la lectura inferencial se logran procesos de comprensión lectora, de atención, de conocimiento lingüístico, todos estos imprescindibles puesto que forman parte de las herramientas que adquieren los niños y las niñas para hacer una actividad lectora exitosa.

La comprensión lectora vista desde la teoría de que el estudiante sólo comprende el tex to cuando es capaz de interpretar lo que allí dice y lo expresa con sus propias palabras referido esto al hecho de entender lo que la docente lee, ya que los estudiantes están iniciando apenas con la decodificación. Evidenciando estos procesos en la tabla de análisis y en la guía de observación. Smith apoya esta teoría ya que destaca "el nivel interactivo de la lectura al afirmar que en la lectura interactúa la información no visual que posee el lector con la información visual que provee el texto" citado por Dubois, refiriéndose no sólo a la lectura inferencial, que aporta a la comprensión lectora sino también al acto de lectura que resulta de, no sólo descifrar los códigos lingüísticos, sino el de la interacción de lo que se entiende en la lectura con sus conocimientos previos.

\section{Discusión y Conclusiones}

La implementación de la propuesta tuvo gran acogida entre los padres de familia, aunque no contaban con computador o servicio de internet en sus hogares, se esforzaron por responder a las actividades virtuales que debían realizar en casa, demostrando esto un logro significativo en el acompañamiento a sus hijos.

De acuerdo a los resultados de la encuesta a padres es evidente que la mayoría de ellos apoyan los procesos lectores de sus hijos, reconociendo en estos procesos su importancia.

Los padres que en un principio pensaban que la tecnología no contribuía en los procesos de aprendizaje de sus hijos, cambiaron de opinión, viendo las posibilidades que encontramos en el recurso virtual.

En la implementación de la propuesta mediante la observación directa se evidenció que para los estudiantes de primera infancia es motivante involucrar la tecnología en este 
caso el computador, para desarrollar procesos lecto-escriturales tanto en el aula como en sus hogares.

La utilización del computador en los procesos lectores evidenció la motivación por participar en las tareas diseñadas para éste fin, comprobado esto en el interés por realizar preguntas acerca de las actividades, las respuestas asertivas a los cuestionamientos realizados por la docente, el deseo de continuar hablando del cuento.

El proyecto impactó de manera positiva en el colegio, al punto de que algunos docentes que no utilizaban los computadores con los que la Secretaría de Educación Distrital dotó la institución, iniciaron el trabajo con éstos e implementaron algunas de las actividades que se realizaron con los estudiantes de preescolar, fomentando la apropiación y el interés por los procesos y proyectos realizados en la institución; con éste espacio se ganó además el interés en los niños llevándolos a ser constructores de su propio aprendizaje, mejorando los procesos lecto-escritos.

La falta de recursos tecnológicos en algunos hogares no fue impedimento para que los estudiantes accedieran a las actividades virtuales que se les sugirieron. Aunque se está en la era de las tecnologías aún hay niños de los llamados "nativos digitales", que debido a las difíciles condiciones económicas, lo más cercano a la tecnología es el televisor, por lo cual este proyecto fue de gran motivación y apoyó significativamente sus procesos, además que fue un gran acercamiento al uso del computador en situaciones reales.

Sugerencias para la propuesta e implementación de futuros proyectos:

El ambiente de aprendizaje b-learning es un modelo que favorece el trabajo con los niños y niñas de primera infancia y en la red se encuentran propuestas adecuadas para el trabajo con los estudiantes, además que existen software para las diferentes dimensiones que se desarrollan en preescolar. Aunque el tiempo de implementación fue corto se fortalecieron procesos lecto-escritos, que se van a evidenciar en un mediano y largo plazo, por lo cual es importante involucrar a los docentes de primaria en el proyecto, para que éste trascienda en la institución.

Dentro de las actividades que implican involucrar a los padres de familia, es importante realizar un taller de acercamiento y asesoramiento del trabajo que se está realizando y del uso de las TIC. Con modelos de aprendizaje b-learning, en estudiantes de primera infancia e inclusive en la primaria es posible desarrollar y fortalecer procesos de atención, memoria, desarrollo del pensamiento matemático, científico e inclusive socio afectivo, introduciendo normas de comportamiento además contribuir en la formación en valores.

Con este modelo de aprendizaje es posible desarrollar procesos comunicativos, argumentativos, propositivos, reflexivos e investigativos. Dado que el b-learning es un método que motiva a los estudiantes, y éste es uno de los aspectos más importantes en torno al aprendizaje, es uno de los métodos que debe fortalecerse en las instituciones educativas en todo los niveles; en Bogotá se están desarrollando procesos apoyados por la Secretaría de Educación Distrital y algunas Universidades para que los profesores aprendan a manejar programas educativos virtuales, empoderándolos de estos y así poder trabajar con los estudiantes en ambientes b-learning, Si bien no todos los docentes manejan la tecnología la idea es fortalecer estos aprendizajes y utilizar éstas de manera cotidiana. 
Sería ideal continuar en el grado primero con los procesos iniciados con los estudiantes de preescolar comparado con los estudiantes que no iniciaron con este proceso y así corroborar las bondades del uso de las TIC en el aprendizaje de la lectura y la escritura.

\section{Referencias}

Bajtín, M. (1998). Estética de la educación verbal. México: Siglo XXI.

Carbonell, T. (2002).La aventura de innovar. Madrid: Morata.

Coaten, N. y Marsh, G.E. (2003). Blended e-learning. Recuperado de http://www.educaweb.com/

Dubois, M.E. (1991). El proceso de la lectura: de la teoría a la práctica. Buenos Aires: Aique.

Dziuban, C.D., Hartman, J.L. y Moskal, P.D. (2004) Blendedlearning educause center for applied research. Recuperado de https://net.educause.edu/

Escorsa, P. (1997). Tecnología e innovación en la empresa. Dirección y gestión. Madrid: Editorial UPC.

Ferreiro, E. (1999). Cultura escrita y educación. México: Fondo de Cultura Económica.

Ferreiro, E. y Teberosky, A. (2003). Los sistemas de escritura en el desarrollo del niño. México: Siglo XXI.

Garrison R. y Kanuka H. (2004). Blendedlearning: uncovering its transformative potential in highereducation. $2^{\text {nd }}$ Quarter Journal, 7(2), 95-125.

Herold, B. (2014). Flexible classrooms: blendedlearning 2.0? Recuperado de: http:// ww.blendedlearningnow.com/

Lerner, D. (2001). Leer y escribir en la escuela: lo real, lo posible y lo necesario. México: Fondo de Cultura Económica.

Paniagua, C. (2013). Tecnología en preescolar: de las iniciativas autogestionadas al diseño de aplicaciones educativas. Edutec Costa Rica, 37, 1-13.

Pérez Gómez. L.C. (2013). Medialab Eafit, un ejemplo de innovación educativa. Ruta Medellín. Recuperado de: http://www.rutanmedellin.org/index.php/es/noticias/item/medialabeafit-un-ejemplo-de-innovacion-educativa

Ramírez, M.S. (2011). Transformando ambientes de aprendizaje en la básica, educación con recursos educativos abiertos. México: Editorial Tecnológico de Monterrey.

Ramírez, M.S. (2012). Modelos y estrategias de enseñanza para ambientes innovadores. México: Editorial Tecnológico de Monterrey.

Ramírez, M.S. y Burgos, J.V. (2010). Recursos educativos abiertos enriquecidos con tecnologías: innovación en la práctica educativa. México: Tecnológico de Monterrey.

Rodríguez, D. (2006). Modelos para la creación y gestión del conocimiento: Una aproximación teórica. Educar, 37, 25-39.

Solano, O. (2013). El aprendizaje combinado y el desarrollo de las habilidades requeridas para la comunicación escrita. Revista Educare, 17(3), 15-34.

Stake, R. (2004). Investigación con estudio de casos. Barcelona: Morata.

Tait, A. (1999). The convergence of distance and conventional education. Some implications for policy. The convergence of distance and conventional education. Pattenrs of flexibility for the individual learner. Nueva York: Routledge.

UNESCO (2005). Hacia las sociedades del conocimiento. París: UNESCO. 
J.Z. Mora Reyes y S.P. Morales Rivera

Villareal, O.J. (2011). Propuesta a niños de preescolar de la institución educativa distrital Floridablanca para el aprendizaje de valores mediante ambientes virtuales. Recuperado de: http://repository.uniminuto.edu:8080/ 


\section{Anexo 1. Desarrollo Propuesta Innovadora}

\begin{tabular}{lccccc}
\hline & \multicolumn{2}{c}{ Estudiantes } & Profesores & Padres & $\begin{array}{c}\text { Revisión de } \\
\text { Literatura }\end{array}$ \\
\hline \multicolumn{1}{|c}{ Instrumentos } & $\begin{array}{c}\text { Observación } \\
\text { directa }\end{array}$ & $\begin{array}{c}\text { Escrito } \\
\text { Dibujo }\end{array}$ & Entrevista & Encuesta & $\begin{array}{c}\text { Análisis de } \\
\text { datos }\end{array}$ \\
\hline \multicolumn{1}{c}{ Categorías } & & & & & Aparici y \\
\hline $\begin{array}{l}\text { Lectura de } \\
\text { imágenes }\end{array}$ & $\mathrm{X}$ & $\mathrm{X}$ & $\mathrm{X}$ & & Mantilla (1998) \\
$\begin{array}{l}\text { Lectura } \\
\text { Inferencial } \\
\begin{array}{l}\text { Comprensión } \\
\text { Lectora }\end{array}\end{array}$ & $\mathrm{X}$ & $\mathrm{X}$ & $\mathrm{X}$ & $\mathrm{M}$ & $\begin{array}{l}\text { Jarmolejo y } \\
\text { Smithez (2006) }\end{array}$ \\
\hline
\end{tabular}

Fuente: Elaboración propia.

\section{Anexo 2. Encuesta a Padres de Familia}

Nombre del estudiante:

Nombre del padre: Edad Ocupación:

Nivel de Educación:

Nombre de la madre: Edad Ocupación:

Nivel de Educación:

1. ¿Cómo está constituida su familia?

2. Porqué es importante lectoescritura en preescolar?

3. ¿leen en su casa? ¿que leen? ¿quien lee?

4. ¿Que lee con su hijo?

5. ¿Cree que su hijo lee?

6. ¿Cree que su hijo escribe?

7. ¿Cree que las cartas de su hijo se pueden leer?

8. ¿Cree usted que con los medios tecnológicos se puede aprender?

9. ¿Que aprenden?

10. ¿Quien apoya en casa los procesos académicos de su hijo?

11. Marque con $\mathrm{X}$ los medios tecnológicos que usan en su hogar:

Teléfono celular _ Televisión _ PC _Portátil_Tablet_Video juegos _ ¿cuáles?

12. ¿Qué uso le dan a esos medio tecnológicos?

Educativo Recreativo Comercial Informativo

13. Comparten en familia estos medios: $\mathrm{Si}$ No ¿Cómo?

14. ¿Tiene servicio de internet en su hogar? Si No

Fuente: Elaboración propia. 


\section{Anexo 3. Tabla de Análisis de Actividades por Componentes}

\begin{tabular}{|c|c|c|c|}
\hline ACTIVIDAD & MotiVACIÓN & CONCENTRACIÓN & INDEPENDENCIA \\
\hline $\begin{array}{l}\text { Actividad A } \\
\text { lectura del } \\
\text { cuento "Choco } \\
\text { encuentra una } \\
\text { mamá” } \\
\text { se realiza } \\
\text { lectura: literal, } \\
\text { inferencial, } \\
\text { predictiva y } \\
\text { descriptiva }\end{array}$ & $\begin{array}{l}\text { El grupo en } \\
\text { general se mostró } \\
\text { motivado, } \\
\text { evidenciado esto } \\
\text { en la atención } \\
\text { que prestaban, } \\
\text { los comentarios } \\
\text { que realizan y las } \\
\text { respuestas } \\
\text { asertivas a los } \\
\text { cuestionamientos } \\
\text { realizados por la } \\
\text { docente. }\end{array}$ & $\begin{array}{l}\text { Por la madurez del } \\
\text { grupo en general } \\
\text { mantiene la atención } \\
\text { por periodos } \\
\text { prolongados } 30 \text { a } 40 \\
\text { minutos), } \\
\text { Evidencian gran } \\
\text { concentración tanto } \\
\text { durante la lectura } \\
\text { como en la } \\
\text { realización del } \\
\text { trabajo escrito }\end{array}$ & $\begin{array}{l}\text { El } 80 \% \text { de los estudiantes } \\
\text { demuestran independencia en } \\
\text { su actitud frente a las } \\
\text { actividades y en la realización } \\
\text { de la actividad propiamente } \\
\text { dicha, el otro } 20 \% \text { es muy } \\
\text { dependiente constantemente } \\
\text { solicitan aceptación de lo que } \\
\text { están trabajando por parte de } \\
\text { la docente y opinión de los } \\
\text { compañeros. }\end{array}$ \\
\hline $\begin{array}{l}\text { Actividad B } \\
\text { Se realizó la } \\
\text { lectura del } \\
\text { cuento “mi papá } \\
\text { no apesta”, esta } \\
\text { lectura se hizo } \\
\text { de manera } \\
\text { literal e } \\
\text { inferencial. }\end{array}$ & $\begin{array}{l}\text { El grupo estaba } \\
\text { muy motivado, la } \\
\text { lectura se realizó } \\
\text { en torno a lo } \\
\text { importante que } \\
\text { son todas las } \\
\text { profesiones y los } \\
\text { oficios, Hubo } \\
\text { gran } \\
\text { participación de } \\
\text { todos los } \\
\text { estudiantes, aún } \\
\text { de los que soy } \\
\text { introvertidos y } \\
\text { tímidos. }\end{array}$ & $\begin{array}{l}\text { El } 80 \% \text { del total de } \\
\text { estudiantes } \\
\text { estuvieron muy } \\
\text { concentrados tanto } \\
\text { por las imágenes } \\
\text { como también } \\
\text { porque debían } \\
\text { contar el cuento a } \\
\text { sus padres y realizar } \\
\text { el dibujo en casa, el } \\
20 \% \text { de los } \\
\text { estudiantes estuvo } \\
\text { disperso, } \\
\text { mantuvieron la } \\
\text { atención tan sólo por } \\
\text { aproximadamente } 10 \\
\text { minutos. }\end{array}$ & $\begin{array}{l}\text { Este aspecto se evaluó, con } \\
\text { respecto al trabajo realizado } \\
\text { en casa, el } 60 \% \text { de los } \\
\text { estudiantes realizaron la } \\
\text { tarea de manera autónoma e } \\
\text { independiente, el } 30 \% \text { de los } \\
\text { padres realizaron el dibujo de } \\
\text { acuerdo a lo que sus hijos les } \\
\text { narraron, el 10\% no realizó } \\
\text { nada porque el estudiante no } \\
\text { se acordó de todo el cuento, } \\
\text { el otro } 10 \% \text { de padres se } \\
\text { disgustaron y escribieron que } \\
\text { ellos no apestaban porque se } \\
\text { bañaban a diario. }\end{array}$ \\
\hline $\begin{array}{l}\text { Actividad C } \\
\text { Creación oral de } \\
\text { un cuento, a } \\
\text { partir } \\
\text { del software. } \\
\text { "Aprendiendo } \\
\text { con } \\
\text { Pipo" } \\
\text { De allí los } \\
\text { estudiantes } \\
\text { escogieron } \\
\text { imágenes y con } \\
\text { ellas iban } \\
\text { narrando el } \\
\text { cuento. }\end{array}$ & $\begin{array}{l}\text { Los estudiantes } \\
\text { estuvieron muy } \\
\text { motivados, todos } \\
\text { querían escoger } \\
\text { la imagen en el } \\
\text { computador, } \\
\text { todos querían } \\
\text { participar } \\
\text { contando que } \\
\text { seguía en la } \\
\text { historia, en fin } \\
\text { fue una actividad } \\
\text { muy creativa y } \\
\text { enriquecedora. }\end{array}$ & $\begin{array}{l}\text { El } 100 \% \text { de los } \\
\text { estudiantes } \\
\text { estuvieron muy } \\
\text { concentrados } \\
\text { llevando el hilo de la } \\
\text { historia, teniendo } \\
\text { coherencia a lo largo } \\
\text { de la narración. }\end{array}$ & $\begin{array}{l}\text { el } 100 \% \text { de los estudiantes } \\
\text { estuvieron muy } \\
\text { independientes, cada cual } \\
\text { aportó de manera individual } \\
\text { y autónoma. }\end{array}$ \\
\hline
\end{tabular}

Fuente: Elaboración propia. 


\section{Anexo 4. Guía de Observación}

\begin{tabular}{|c|c|c|c|c|c|c|c|c|c|}
\hline & N1 & N2 & N3 & N4 & N5 & N6 & N7 & N8 & N9 \\
\hline $\begin{array}{l}\text { Contesta asertivamente las preguntas relacionadas } \\
\text { con la actividad }\end{array}$ & & $\mathrm{X}$ & $\mathrm{X}$ & $\mathrm{X}$ & $\mathrm{X}$ & & $\mathrm{X}$ & $\mathrm{X}$ & $\mathrm{X}$ \\
\hline Lee imágenes y realiza relatos acerca de ellas & & & $\mathrm{X}$ & $\mathrm{X}$ & $\mathrm{X}$ & $\mathrm{X}$ & X & $X$ & \\
\hline Participa en la lectura inferencial de diferente textos & & $\mathrm{X}$ & $\mathrm{X}$ & & $\mathrm{X}$ & & & & $\mathrm{X}$ \\
\hline $\begin{array}{l}\text { Con sus acciones demuestra avances en sus procesos } \\
\text { lecto-escritos }\end{array}$ & $\mathrm{X}$ & $\mathrm{X}$ & $\mathrm{X}$ & $\mathrm{X}$ & $\mathrm{X}$ & $\mathrm{X}$ & $\mathrm{X}$ & & $\mathrm{X}$ \\
\hline
\end{tabular}

Fuente: Elaboración propia. 